Faculty of Science

Faculty Publications

Standardized Stirring for Small Scale Surveys

Isaac Omari, Mathias Paul, \& J. Scott McIndoe

March 2021

(C) 2021 Isaac Omari et al. This is an open access article distributed under the terms of the Creative Commons Attribution License. https://creativecommons.org/licenses/by/4.0/

This article was originally published at:

https://doi.org/10.1002/cmtd.202000066

Citation for this paper:

Omari, I., Paul, M., \& McIndoe, J. S. (2021). Standardized Stirring for Small Scale Surveys. Chemistry-Methods, 1(3), 173-176. https://doi.org/10.1002/cmtd.202000066. 


\title{
Standardized Stirring for Small Scale Surveys**
}

\author{
Isaac Omari, Mathias Paul, and J. Scott Mclndoe*[a]
}

\begin{abstract}
Stirring rates in heterogeneous catalytic reactions have an effect on reaction rates. When conducting small-scale surveys using a single central stir plate, reaction vessels in different positions experience slightly different levels and patterns of agitation. We probed this effect by running the same reaction 40 times, varying the stir rate (fast/slow) and the vial position using two 3D-printed vial holders. We found variability of conversion (measured mass spectrometrically) to be approximately two times higher for vials placed somewhat randomly in comparison to when vials are consistently placed at a fixed distance from the centre of the stir plate, but the effect was relatively small and could be minimized by using a high stir rate. For those experimenters wishing to completely eliminate differential stirring as a cause for variation in results, the 3D-printed circular array we designed is recommended over a conventional rectangular array.
\end{abstract}

\section{Introduction}

Catalytic reactions are sensitive to a wide range of experimental conditions, even in homogeneous systems. ${ }^{[1-9]}$ These conditions include variables, such as concentration of reactants and catalyst $^{[10]}$ stirring rate $^{[11]}$ reaction time and temperature, ${ }^{[12]}$ which contribute to the outcome of a catalytic system after optimization. This study focuses on the influence of stirring in a small-scale cross-coupling reaction. The effect of stirring on the rate of coupling reactions is well-established. ${ }^{[13-15]}$ With reference to this, we noticed significant discrepancies in reaction behavior in a variant of the copper-free Sonogashira reaction ${ }^{[16-25]}$ when a heterogeneous base was used, with what seemed like minor differences in stirring. Herein, we therefore delved deeper into this topic by probing the effect of changing the distance of a reaction vial from the center of a stir plate. We studied the reaction at low concentration using ESI-MS ${ }^{[26-30]}$ and

[a] Dr. I. Omari, Dr. M. Paul, Prof. J. S. McIndoe

Department of Chemistry

University of Victoria

P.O. Box 1700 STN CSC

Victoria, BC V8W 2 Y2 (Canada)

E-mail: mcindoe@uvic.ca

[**] A previous version of this manuscript has been deposited on a preprint server (https://doi.org/10.26434/chemrxiv.13289354.v2)

6upporting information for this article is available on the WWW under https://doi.org/10.1002/cmtd.202000066

of (c) 2021 The Authors. Published by Wiley-VCH GmbH. This is an open access article under the terms of the Creative Commons Attribution Non-Commercial NoDerivs License, which permits use and distribution in any medium, provided the original work is properly cited, the use is non-commercial and no modifications or adaptations are made. concluded that while the differences were small, they were significant enough to advise taking precautions to avoid them when optimizing reaction conditions. To this end, we designed, and 3D-printed linear and circular vial holders for 10 and 20 vials respectively. The circular vial holder is expected to ensure identical stirring conditions and thus, maximize the reproducibility and reliability of small-scale screening experiments, ${ }^{[31-35]}$ where small differences may attract significant attention. In addition, the vial holders can be scaled up or down easily (using the software corresponding to the $3 \mathrm{D}$ printer of choice) to handle larger or smaller reaction vials.

\section{Results and Discussion}

In searching for heterogeneous variants of the copper-free Sonogashira reaction reported previously, ${ }_{1}^{[16]}$ we reasoned that changing the base used from 1,8-diazabicyclo[5.4.0]undec-7ene (DBU) to cesium carbonate $\left(\mathrm{Cs}_{2} \mathrm{CO}_{3}\right)$ would be the simplest modification. However, under diluted conditions optimized suitable for ESI-MS, $\mathrm{Cs}_{2} \mathrm{CO}_{3}$ completely dissolved. Accordingly, the less soluble calcium carbonate $\left(\mathrm{CaCO}_{3}\right)$ was selected.

The experimental conditions were optimized to accommodate $\mathrm{CaCO}_{3}$ (Scheme 1), and reactions were monitored in realtime at different stirring rates $(60 \mathrm{rpm}$ vs. $400 \mathrm{rpm}$; see Movies S1-S4) but otherwise under the same conditions. The differences between the reactions were subtle but real (see Figure 1), with the faster stir rate resulting in a slightly higher yield.

It is common in optimization of organometallic reactions (different solvents, additives, ligands, or metal centers) to charge e.g. 24 vials in a $6 \times 4$ grid and stir them all together from a central point. The distance of a stir bar from the center of the stir plate determines exactly how the reaction is stirred. In a worst-case scenario, all reactions within such an optimization attempt could stir differently, and if this difference led to significant differences in rate, inaccurate conclusions could be drawn regarding the next optimization step. Due to this, we probed the extent of error in differently stirred reactions. A vial holder that can hold 10 reactions at once but at different positions (see Supporting Information) from each other (0$75 \mathrm{~mm}$ away from the center) was designed as part of this investigation. In this setup, the vial directly next to the center and the vial farthest from the center were stirred most consistently, while in most others the stir bar performed a clicking or walking motion. To compare these 10 differently stirred reactions, we designed another holder for equal stirring (see Figure 2). The vial is held in place by the cap and the unit is designed for a tight fit. All experiments were done using 3 dram $(11 \mathrm{~mL}$ ) vials of dimensions $65 \mathrm{~mm}(\mathrm{~h}) \times 19 \mathrm{~mm}(\mathrm{~d})$ and stirrer bars of dimensions $15 \mathrm{~mm}(\mathrm{~h}) \times 4.5 \mathrm{~mm}(\mathrm{~d})$, but the 

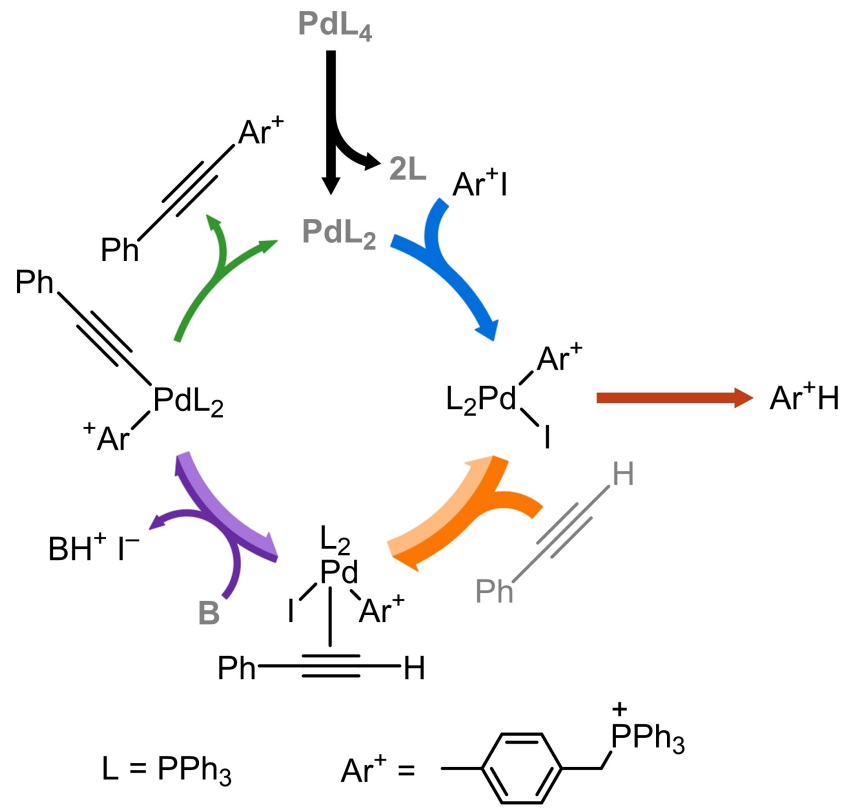

Scheme 1. The copper-free Sonogashira reaction, employing a permanently charged aryl iodide for mass spectrometric reaction monitoring $\left(\operatorname{Ar}^{+} \mathrm{I}\right)$, phenyl acetylene, tetrakis(triphenylphosphine)palladium(0) as the precatalyst and calcium carbonate as the heterogeneous base (B). All species in black are detectable by ESI-MS. Species in grey are neutral and are thus undetectable. The catalytic cycle was generated using catacycle.com. ${ }^{[36]}$
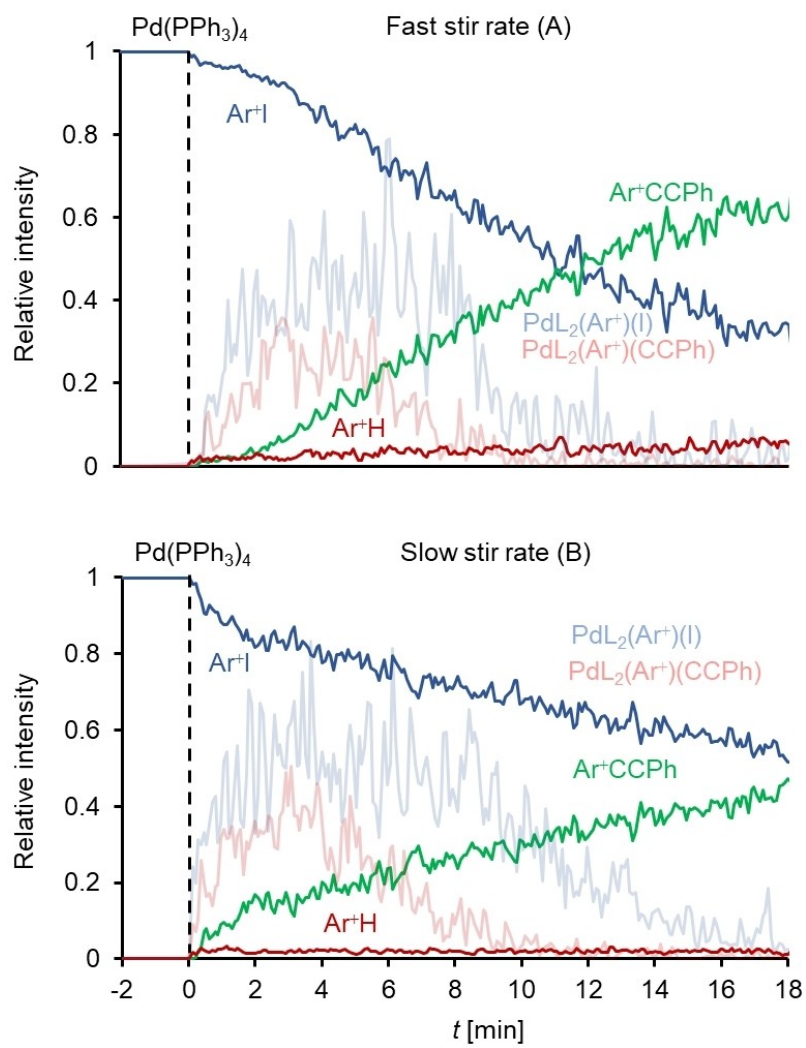

Figure 1. Two kinetic profiles of the copper-free Sonogashira reaction with $6 \mathrm{~mol} \%$ of catalyst being employed. Top, at a relatively fast stirring rate and bottom, at a relatively slow stirring rate. For the purpose of illustration, the intensities of palladium intermediates were multiplied by 100 . Traces were normalized to the sum of all species. This data was obtained using the full scan mode on a triple-quadrupole mass spectrometer.
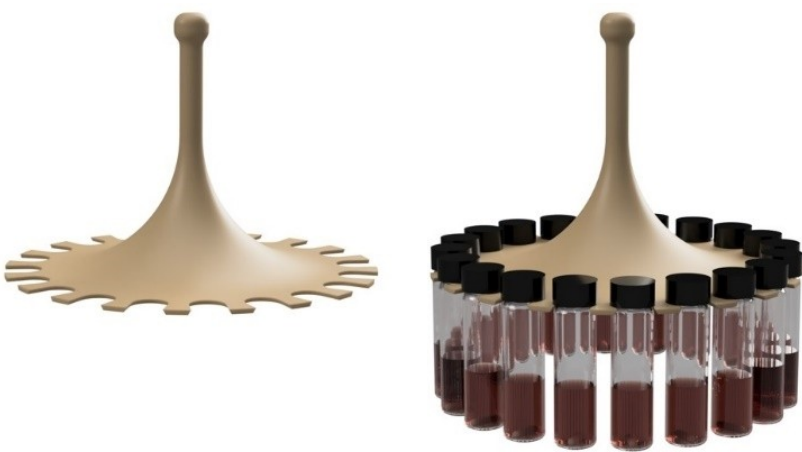

Figure 2. Left: empty 3D-printed 20-vial holder and right: vial holder loaded with vials.

design can be easily rescaled to accommodate other sizes of vial or stirrer bar. STL files are available in the Supporting Information for 10 and 20-vial circular holders. The vial holder can be used to place the vials in the oil bath unsupported or can be clamped at the desired height using the central pillar. It is compatible with heated or cooled reactions. Commercial circular vial holders for hot plates are available, but at a price approximately $100 \times$ that of the design in Figure 2 .

For consistency, ten vials in this configuration were placed in every other slot at the same distance from the center as the one farthest from the center in the setup for unequal stirring. Figure 3 and Figure 4 depict the outcome obtained by means of ESI-MS after reactions were performed in vials using 3Dprinted linear $(0,24,34,41,48,53,60,64,71,75 \mathrm{~mm})$ and circular vial holders (all at $72 \mathrm{~mm}$ ). Two separate sets of ten experiments were conducted at two different stirring rates, for

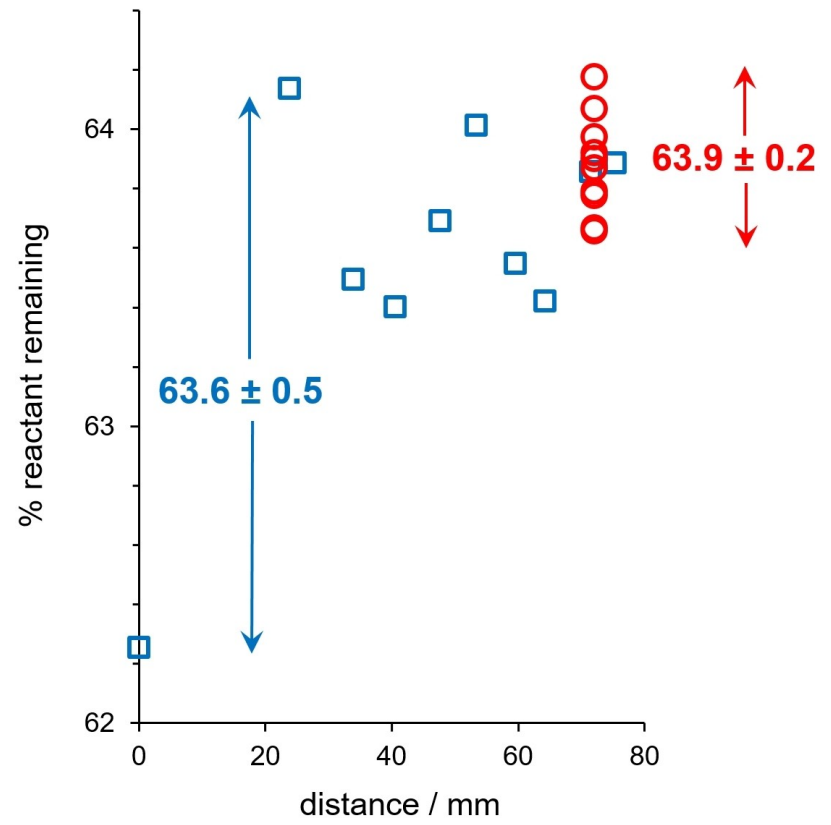

Figure 3. Percentage of remaining reactant based on distance of vial from central stirring point at a slow stir rate $(60 \mathrm{rpm})$. Blue squares are vials mounted in the linear holder; red circles are those mounted in the circular holder. 


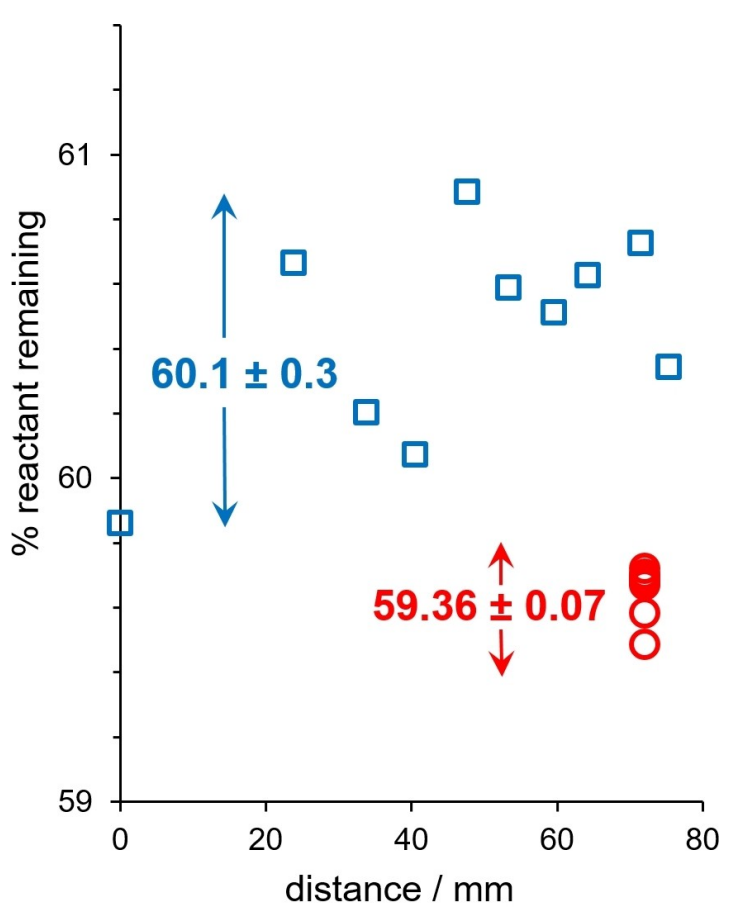

Figure 4. Percentage of remaining reactant based on distance of vial from central stirring point at a fast stir rate $(400 \mathrm{rpm})$. Blue squares are vials mounted in the linear holder; red circles are those mounted in the circular holder.

a total of 40 different determinations of yield at a fixed reaction time point (10 minutes after addition of catalyst). Figure 3 shows the results for the slow stirring rate $(60 \mathrm{rpm})$.

The reaction was impressively reproducible for both sets of 10 experiments, with slightly greater scatter for the vials mounted at different distances from the central stirring point (blue squares, $63.6 \% \pm 0.5 \%$ ) compared to those at fixed distances (red circles, $63.9 \% \pm 0.2 \%$ ).

When the vials were stirred rapidly, variation fell for both sets of experiments by approximately a factor of two (see Figure 4). The range was again less for the vials in the circular holder. Data were also collected in all cases for the appearance of cross-coupled product and of the hydrodehalogenation byproduct, and the trends observed above were reflected in these results, namely the same increased variation where the distance from the central stirring point was varied (see Supporting Information for more details). It is likely the case that most experimentalists will be perfectly content with the level of variability observed in this experiment as it likely falls well within the normal range of variation for a given experiment, and they are looking for much more significant changes than observed here, but it is probably worth testing the variation in their own setup by doing the same reaction across their whole array if they suspect stirring effects are perturbing results.

\section{Conclusion}

Differential stirring effects were detected in small-scale heterogeneous catalytic reactions based on distance of the reaction vessel from the central stirring point. However, these effects were small and could be mitigated (though not eliminated) by ensuring reasonably fast stir rates. Circular vial holders of variable size can be 3D printed inexpensively and without the use of support material to reduce stirring effects to a minimum and to improve reproducibility in small-scale surveys.

\section{Experimental Section}

All chemicals were purchased from Sigma-Aldrich and used as received except for the HPLC grade methanol and tetrahydrofuran which were dried over calcium hydride and distilled under nitrogen before use. Argon (UHP200) was obtained from Airgas (Calgary, Canada) and employed without further purification.

In this study, both on-line and off-line experiments were carried out for fast and slow stir rate reactions. For on-line experiments, phenylacetylene $(12 \mu \mathrm{mol}, 1.2 \mathrm{eq})$ and calcium carbonate $(0.5 \mathrm{mmol}, 50 \mathrm{eq})$ were added to a solution of $\left[\mathrm{I}\left(\mathrm{C}_{6} \mathrm{H}_{4}\right) \mathrm{CH}_{2} \mathrm{PPh}_{3}\right]\left[\mathrm{PF}_{6}\right]$ $(10 \mu \mathrm{mol}, 1 \mathrm{eq})$ in methanol $(7 \mathrm{~mL})$ in a vial charged with a stir bar under inert conditions and brought to $70^{\circ} \mathrm{C}$ in an oil bath. The reaction was initiated by addition of a THF solution of $\mathrm{Pd}\left(\mathrm{PPh}_{3}\right)_{4}$ ( $6 \mathrm{~mol} \%)$ by syringe through a septum. The vial was pressurized with 3 psi argon and the reaction solution was transferred into a mass spectrometer through PEEK tubing. ${ }^{[28,37]}$ An IKA C-MAG HS 7 hot plate magnetic stirrer was used for all experiments. Stirring rate was set to $400 \mathrm{rpm}$ for fast stirring reactions and $60 \mathrm{rpm}$ for slow stirring reactions. For off-line experiments, all reagents were prepared as described for the on-line experiments and placed in 20 vials with stir bars under inert conditions in a glovebox; however, the experiments were conducted outside the glovebox. Two sets of vials ( 10 vials per set) from the glovebox were arranged in a linear and circular vial holder (these vial holders were printed on a Creality Ender 3 printer using PLA filament); immersed in a heated oil-bath $\left(70^{\circ} \mathrm{C}\right)$ for 10 minutes at both fast and slow stirring rates. The reaction was quenched after $10 \mathrm{~min}$ by placing the hot vials in an ice-bath for $20 \mathrm{~min}$; the quenched samples were filtered and diluted with cold methanol to $1 \% \mathrm{v} / \mathrm{v}$. These samples were loaded into a Hamilton GASTIGHT syringe and transferred through PEEK tubing directly into the mass spectrometer at a rate of $10 \mu \mathrm{L} /$ $\min$.

Electrospray ionization mass spectra were collected on a Waters Acquity Triple Quadrupole Detector mass spectrometer in positive ion mode. Instrument source parameters were as follows: capillary voltage was held at $3 \mathrm{kV}$, cone voltage at $10 \mathrm{~V}$, and extraction cone at $0.5 \mathrm{~V}$. The following settings were used for desolvation conditions: desolvation gas flow rate, $200 \mathrm{~L} / \mathrm{h}$; cone gas flow rate, $100 \mathrm{~L} / \mathrm{h}$; source temperature, $80^{\circ} \mathrm{C}$; desolvation temperature, $200^{\circ} \mathrm{C}$. The detector gain was set to $470 \mathrm{~V}$. Scan time was set to $5 \mathrm{~s}$, with an inter-scan time of $0.5 \mathrm{~s}$. Low and high resolutions were set to 17 . The relative intensities of species recorded were used for percent yield calculation. Percent yield was calculated by multiplying the ratio of the intensity of species (intensity of species of interest: total intensity of all species) by 100 . 


\section{Acknowledgements}

J.S.M. thanks the NSERC Discovery program for operational funding and CFI, BCKDF and the University of Victoria for infrastructural support.

\section{Conflict of Interest}

The authors declare no conflict of interest.

Keywords: 3D-printed circular arrays · heterogeneous catalysis . mass spectrometry $\cdot$ small-scale surveys $\cdot$ stirring rate

[1] R. Y. Liu, J. M. Dennis, S. L. Buchwald, J. Am. Chem. Soc. 2020, 142, 4500 4507

[2] H. Pang, Y. Wang, F. Gallou, B. H. Lipshutz, J. Am. Chem. Soc. 2019, 141, 17117-17124.

[3] S. Handa, B. Jin, P. P. Bora, Y. Wang, X. Zhang, F. Gallou, J. Reilly, B. H. Lipshutz, ACS Catal. 2019, 9, 2423-2431.

[4] S. J. Ton, D. E. Fogg, ACS Catal. 2019, 9, 11329-11334.

[5] M. Anand, J. K. Nørskov, ACS Catal. 2020, 10, 336-345.

[6] G. Prieto, ChemSusChem 2017, 10, 1056-1070.

[7] A. Cook, S. Prakash, Y. L. Zheng, S. G. Newman, J. Am. Chem. Soc. 2020, $142,8109-8115$

[8] T. Verheyen, L. Van Turnhout, J. K. Vandavasi, E. S. Isbrandt, W. M. De Borggraeve, S. G. Newman, J. Am. Chem. Soc. 2019, 141, 6869-6874.

[9] A. Joshi, H. S. Zijlstra, S. Collins, J. S. McIndoe, ACS Catal. 2020, 10, 71957206.

[10] A. Zapf, M. Beller, Chem. Eur. J. 2001, 7, 2908-2915.

[11] A. S. Castanet, F. Colobert, J. R. Desmurs, T. Schlama, J. Mol. Catal. A 2002, 481-487.

[12] Z. Li, F. Ke, H. Deng, H. Xu, H. Xiang, X. Zhou, Org. Biomol. Chem. 2013, 11, 2943-2946.

[13] J. Luo, Y. Wu, H. S. Zijlstra, D. A. Harrington, J. S. McIndoe, Catal. Sci. Technol. 2017, 7, 2609.

[14] A. J. J. Lennox, G. C. Lloyd-Jones, J. Am. Chem. Soc. 2012, 134, 74317441

[15] J. A. Gonzalez, O. M. Ogba, G. F. Morehouse, N. Rosson, K. N. Houk, A. G. Leach, P. H. Y. Cheong, M. D. Burke, G. C. Lloyd-Jones, Nat. Chem. 2016 8, 1067-1075.
[16] Z. Ahmadi, L. P. E. Yunker, A. G. Oliver, J. S. Mclndoe, Dalton Trans. 2015, 44, 20367-20375.

[17] M. Gazvoda, M. Virant, B. Pinter, J. Košmrlj, Nat. Commun. 2018, 9, 1-9.

[18] T. Ljungdahl, T. Bennur, A. Dallas, H. Emtenäs, J. Mårtensson, Organometallics 2008, 27, 2490-2498.

[19] K. L. Vikse, Z. Ahmadi, C. C. Manning, D. A. Harrington, J. S. Mclndoe, Angew. Chem. Int. Ed. 2011, 50, 8304-8306; Angew. Chem. 2011, 123, 8454-8456.

[20] A. Jutand, S. Négri, A. Principaud, Eur. J. Inorg. Chem. 2005, 2005, 631635.

[21] D. Gelman, S. L. Buchwald, Angew. Chem. Int. Ed. 2003, 42, 5993-5996; Angew. Chem. 2003, 115, 6175-6178.

[22] S. Urgaonkar, J. G. Verkade, J. Org. Chem. 2004, 69, 5752-5755.

[23] B. H. Lipshutz, D. W. Chung, B. Rich, Org. Lett. 2008, 10, 3793-3796.

[24] M. Karak, L. C. A. Barbosa, G. C. Hargaden, RSC Adv. 2014, 4, 5344253466.

[25] A. Komáromi, Z. Novák, Chem. Commun. 2008, 4968-4970.

[26] T. Rob, D. J. Wilson, Eur. J. Mass Spectrom. 2012, 18, 205-214.

[27] C. lacobucci, S. Reale, F. De Angelis, Angew. Chem. Int. Ed. 2016, 55 2980-2993; Angew. Chem. 2016, 128, 3032-3045.

[28] K. L. Vikse, Z. Ahmadi, J. Luo, N. Van Der Wal, K. Daze, N. Taylor, J. S. McIndoe, Int. J. Mass Spectrom. 2012, 323-324, 8-13.

[29] R. Theron, Y. Wu, L. P. E. Yunker, A. V. Hesketh, I. Pernik, A. S. Weller, J. S. McIndoe, ACS Catal. 2016, 6, 6911-6917.

[30] D. B. Eremin, V. P. Ananikov, Organometallics 2014, 33, 6352-6357.

[31] G. J. Noordzij, C. H. J. T. Dietz, N. Leoné, C. H. R. M. Wilsens, S. Rastogi, RSC Adv. 2018, 8, 39818-39828.

[32] M. D. Truppo, J. D. Rozzell, J. C. Moore, N. J. Turner, Org. Biomol. Chem. 2009, 7, 395-398.

[33] A. B. Santanilla, E. L. Regalado, T. Pereira, M. Shevlin, K. Bateman, L. C. Campeau, J. Schneeweis, S. Berritt, Z. C. Shi, P. Nantermet, Y. Liu, R. Helmy, C. J. Welch, P. Vachal, I. W. Davies, T. Cernak, S. D. Dreher, Science 2015, 347, 49-53.

[34] E. S. Isbrandt, R. J. Sullivan, S. G. Newman, Angew. Chem. Int. Ed. 2019, $58,7180-7191$.

[35] S. Monfette, J. M. Blacquiere, D. E. Fogg, Organometallics 2011, 30, 3642.

[36] J. McFarlane, B. Henderson, S. Donnecke, J. S. McIndoe, Organometallics 2019, 38, 4051-4053.

[37] L. P. E. Yunker, R. L. Stoddard, J. S. Mclndoe, J. Mass Spectrom. 2014, 49, $1-8$.

Manuscript received: November 26, 2020

Version of record online: 